\title{
Pilot Production of Photonic Devices by Roll-to-Roll Nanoimprinting
}

\author{
Tapio Mäkelä, Tomi Haatainen and Jouni Ahopelto \\ VTT Technical Research Centre of Finland \\ Tietotie 3, 02150 Espoo, Finland \\ jouni.ahopelto@vtt.fi
}

\begin{abstract}
Waveguides for back lighting have been produced using roll-to-roll nanoimprinting. More than 1000 pieces were fabricated and every $50^{\text {th }}$ device was analysed by confocal microscope, atomic force microscopy and luminance measurements. The properties of the devices are of commercial quality, confirming that roll-to-roll nanoimprinting has potential for high throughput production.
\end{abstract}

Keyword: Nanoimprint, roll to roll, diffractive element, backlight device

\section{Introduction}

Roll-to-roll nanoimprinting is a promising method for large scale manufacturing of photonic devices. [1-7]. We report on the results of small scale production of diffractive optical elements suitable for backlighting applications [8]. The element consists of a thin waveguide with tens of thousands of different diffractive structures which are used to control the light incoming through the waveguide and to direct it homogeneously outwards from the surface of the element. One of such sub-elements is shown in the Fig. 1. For piloting we have fabricated more than one thousand diffractive waveguides and analysed the optical performance of the elements.

\section{Experimental}

A custom made roll to roll nanoimprinting tool [9] was used in the experiments, shown in Fig. 2. The pressure used was $8 \mathrm{MPa}$, the imprinting speed was $0.6 \mathrm{~m} / \mathrm{min}$ and the temperature was 110 C. The imprinting speed of $0.6 \mathrm{~m} / \mathrm{min}$ corresponds roughly to an imprinting time of $0.3 \mathrm{~s}$ with the contact length between rolls (NIP) of $3 \mathrm{~mm}$. The upper roll is heated up to the glass transition temperature $\mathrm{T}_{\mathrm{g}}$ and the film is cooled close to the room temperature within seconds by the cold backing roll. The patterns are transferred using a flexible Ni-stamp [10] which is clamped mechanically on the upper metal roll. The height of the patterns on the shim is $1.6 \mu \mathrm{m} .375$ um thick and $50 \mathrm{~mm}$ wide PMMA foil was used as the web.

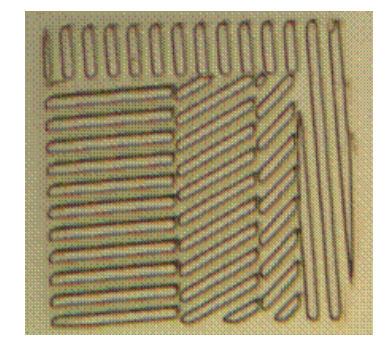

Fig. 1 Optical micrograph of a single diffractive element used in a backlighting device.

\section{Results}

Every $50^{\text {th }}$ device was analysed using confocal and atomic force microscopy. The average depth of the imprinted patterns was 1.3-1.4 $\mu \mathrm{m}$. The optical properties of the devices were analysed by luminance measurements, see Fig. 3. The devices showed good homogeneity and high optical quality. No sign of stamp wear was observed. The piloting 
experiment supports roll-to-roll nanoimprinting being a promising candidate for low cost production method for photonic devices.

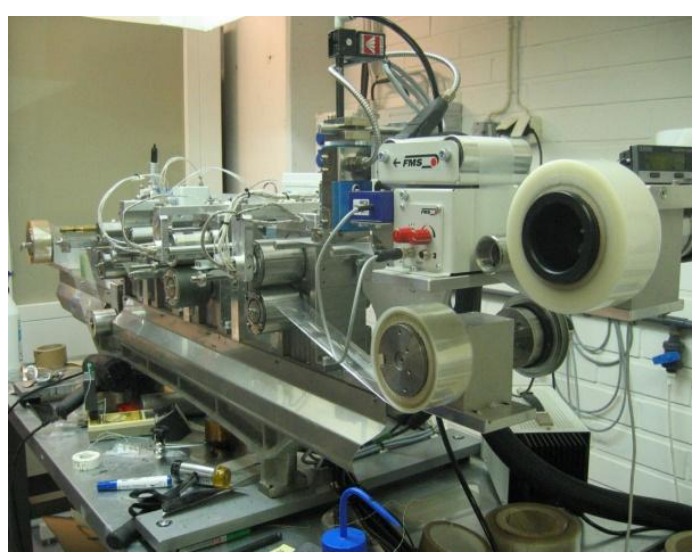

Fig. 2 Laboratory scale Roll-to-Roll nanoimprinting tool for pilot production [8].

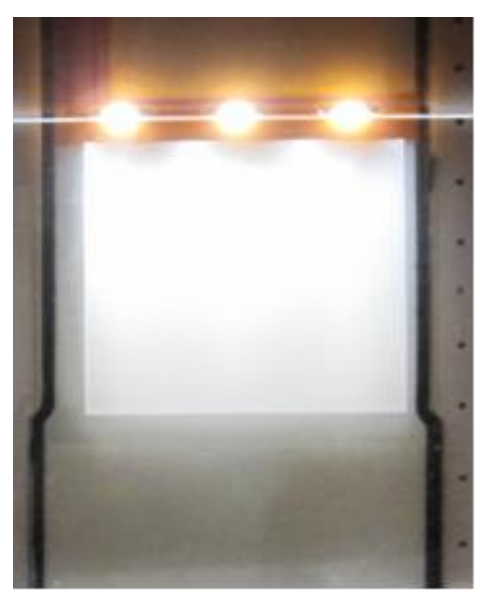

Fig. 3 Backlight device under test. Every $50^{\text {th }}$ device was characterised. The quality of all the backlights was high enough for commercial use

\section{Acknowledgements}

The authors would like to acknowledge the fruitful discussions with K. Rinko. T. Tuohisaari and J. Oravasaari, and the financial support by the European Commission through the NaPANIL project.

\section{References}

[1] S-M. Seo, Tae-il Kim, Hong H. Lee, Microelectronic Engineering 84 (2007) 567-57.

[2] J. Lee, S. Park, K. Choi and G. Kim, Microelectronic Engineering 85 (2008) 861.

[3] S. H. Ahn and L. Jay Guo, Adv. Mater. 20 (2008) 2044-2049.

[4] C-Y. Chang, S-Y. Yang and M-H.Chu, Microelectronic Engineering 84 (2007) 355.

[5] S. Kim and S. Kang, J. Phys. D: Appl. Phys. 36 (2003) 2451-2456.

[6] T. Mäkelä, T. Haatainen, P. Majander and J. Ahopelto, Microelectronic Engineering 84 (2007) 877.

[7] T. Mäkelä, T. Haatainen, P. Majander, J. Ahopelto and V. Lambertini, Jpn. J. Appl. Phys. 47 (2008) 5142-5144.

[8] www.modilis.com

[9] T. Mäkelä et al., Microelectronic Engineering (2011), doi:10.1016/j.mee.2011.02.016, in press; www.ptmtec.com.

[10] T. Haatainen, P. Majander, T. Riekkinen, J. Ahopelto, Microelectronic Engineering 83 (2006) 948. 